\title{
A novel method to calculate the gas adsorption of mixed minerals
}

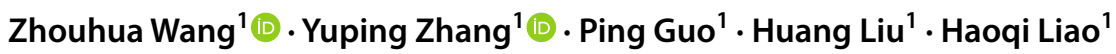

Received: 3 November 2019 / Accepted: 17 January 2020 / Published online: 30 January 2020

(c) Springer Nature Switzerland AG 2020

\begin{abstract}
Five groups of methane isotherm adsorption tests were carried out at $61^{\circ} \mathrm{C}$ under a pressure range of $0-25 \mathrm{MPa}$, including four groups of pure clay minerals (illite, montmorillonite, chlorite, kaolinite, for brief they are expressed as III, Mont, Chl, and Kaol respectively) and a group of mixed minerals by four pure clay minerals in equal mass ratio. The experimental results showed the order of methane adsorption of pure clay minerals: Kaol > III > Mont >Chl. And the composition of clay minerals was obtained by XRD experiments. The result showed that the four samples were of high purity, both of which were greater than $90 \%$. In addition, the results of low-pressure nitrogen adsorption experiments showed the order of specific surface area: $\mathrm{KaOl}>\mathrm{III}>\mathrm{Mont}>\mathrm{Chl}$, which is consistent with the order of methane adsorption. The methane adsorption is positively correlated to the specific surface area. The adsorption data was fitted to the Langmuir-Freundlich model to establish the method to calculate the adsorption of mixed minerals. The result showed that the parameters of the adsorption model of mixed clay minerals can be obtained by summing the parameters of the adsorption model of the pure minerals contained in the mixture according to their constituent mass ratio and the feasibility of this result was also verified by literature data. Overall, once the mass ratio in mixed clay minerals gets known, its theoretical adsorption can be calculated.
\end{abstract}

Keywords Kaolinite $\cdot$ Montmorillonite $\cdot$ Chlorite $\cdot$ Illite $\cdot$ Methane $\cdot$ Adsorption law

\section{List of symbols}

$m_{a b s} \quad$ Absolute adsorption (g)

$m_{\text {excess }}$ Excess adsorption (g)

$V_{a} \quad$ Adsorption phase volume $\left(\mathrm{cm}^{3}\right)$

$\rho_{g} \quad$ Free gas density $\left(\mathrm{g} \mathrm{cm}^{-3}\right)$

$\rho_{a} \quad$ Adsorption phase density $\left(\mathrm{g} \mathrm{cm}^{-3}\right)$

$V \quad$ Adsorption volume per unit $\left(\mathrm{cm}^{3} \mathrm{~g}^{-1}\right)$

$P \quad$ Gas equilibrium pressure ( $\mathrm{MPa})$

$b \quad$ A constant related to temperature and adsorption heat

$V_{L} \quad$ Langmuir volume, reflecting the maximum adsorption capacity of shale $\left(\mathrm{cm}^{3} \mathrm{~g}^{-1}\right)$

$m \quad$ A constant related to heterogeneity of adsorbent

$K_{i} \quad$ Parameter value, $\mathrm{K}$, of $\mathrm{i}$ type of pure clay minerals $y_{i} \quad$ The mass ratio of the $i$ component in the mixed minerals

$n \quad$ The number of the types of pure clay minerals in the mixed minerals

\section{Introduction}

The adsorption is one of the most important forms of methane in shale, and the content of adsorption gas is as high as $20-85 \%$ of the total gas [1-3]. The gas is mainly adsorbed on the surface of organic particles and clay minerals $[1,4,5]$. Studies on the adsorption of methane by organic matter in shale have been elaborated in many scholars' articles. This paper focuses on adsorption of methane on four pure clay minerals (III, Mont, Chl, and Kaol) and their mixture. The shale is rich in inorganic clay

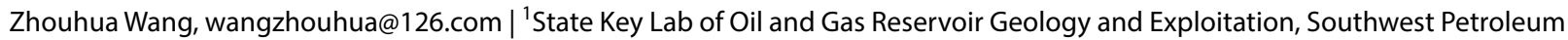
University, No. 8 Xindu Avenue, Chengdu 610500, China. 
minerals [6] and plays an important role in the adsorption of methane on shale [7]. Clay minerals contribute differently to the adsorption capacity, and their adsorption depends on the type of clay [8-12]. The composition and content of clay minerals (mainly III, Mont, Chl, and Kaol) in different shale reservoirs are quite different, affecting the adsorption capacity of shale gas. It is the main purpose of this paper to study how to calculate the gas adsorption of mixed clay minerals through that of pure clay mineral and the adsorption difference among pure clay minerals.

Clay minerals are second only to organic adsorbents with a strong adsorption capacity. Clay minerals are rich in pores, providing adsorption site. The contribution of clay minerals to shale pores is obvious, and the plane porosity of clay can even reach $16 \%$ [8]. The pores of clay mineral are major contributors to space of shale gas reservoir and gas adsorption, especially in the low-maturation and maturation stages of reservoirs with low level of organic matter [13-15]. The adsorption capacity of clay minerals can be comparable to that of shale matrix due to abundant internal surface area [5, 12, 16-21]. In addition, it was observed by Yang et al. [22] that the average contribution of clay minerals to methane adsorption capacity is about $28.6 \%$. Rexer et al. [23] estimated that clay minerals contribute about $45-60 \%$ to methane adsorption capacity, indicating that clay minerals play important roles in the methane adsorption.

The pore structure of clay minerals varies according to the evolution degree of the reservoir. Through the compaction during diagenesis, micropores with different shapes and sizes can be formed in clay minerals. The more micropores and nanopores the clay minerals have, the larger the specific surface area, because more surface area is associated with smaller pores, which can provide more surface adsorption sites for methane [8]. As the pore size of the clay increases, the adsorption rate of methane decreases [6]. It was concluded by Ross and Bustin [18] that clay minerals with higher pore volume and larger specific surface area have greater adsorption capacity. The pores with different size of different clay minerals are arrayed to each other, resulting in different gas adsorption effect [8].

The structural characteristics and physicochemical properties of clay minerals partially control the adsorption capacity and gas enrichment ability [8]. Different types of clay minerals have different adsorption capacities for methane, which may be related to the microstructure of clay minerals. The specific surface area is the main factor affecting the methane adsorption capacity of different types of clay minerals [9]. Some scholars have concluded that Mont has the greatest adsorption capacity for methane $[8,12,24,25]$, mainly due to its apparent and internal surface area. The stratification and flocculation of clay minerals increase the specific surface area and pore volume of the shale, providing more adsorption sites. For example, Mont and III-Mont have relatively high specific surface area because they not only have an external surface area, but also have more internal surface area provided by the interlayer structure [3]. Ji et al. [26, 27] studied the methane adsorption capacity of clay minerals: Mont $>\mathrm{KaOl}>\mathrm{III}$, which is consistent with the order of specific surface area (Mont: $76.413 \mathrm{~m}^{2} \mathrm{~g}^{-1}$, Kaol: $15.281 \mathrm{~m}^{2} \mathrm{~g}^{-1}$, III: $\left.11.738 \mathrm{~m}^{2} \mathrm{~g}^{-1}\right)$. The methane adsorption of $\mathrm{Ca}^{2+}$-Mont, Kaol and III was studied by Liu, D. et al. at $60^{\circ} \mathrm{C}$ and up to 18.0 MPa, all showing high adsorption capacity. The Langmuir adsorption volume $\left(\mathrm{V}_{\mathrm{L}}\right)$ follows the order: Mont $(6.01$ $\left.\mathrm{cm}^{3} \mathrm{~g}^{-1}\right)>\operatorname{Kaol}\left(3.88 \mathrm{~cm}^{3} \mathrm{~g}^{-1}\right)>$ III $\left(2.22 \mathrm{~cm}^{3} \mathrm{~g}^{-1}\right)$ [7]. Mont plays an important role in the adsorption and storage of methane in shale $[7,28,29]$. Ross and Bustin [30] studied the adsorption capacity of clay minerals in Jurassic and Devonian-Mississippian shale in Canada, and obtained the order: III has higher methane adsorption than Mont and Kaol with the strongest methane adsorption capacity. Lu et al. [31] measured the adsorption capacity of several shale samples from Devonian and pure III, and the maximum methane adsorption of pure $\mathrm{III}$ at $37.8^{\circ} \mathrm{C}$ and $\leq 8.0 \mathrm{MPa}$ was higher than that of shale samples from Michigan, West Virginia and Kentucky. They concluded that III has significant methane adsorption in addition to kerogen in shale, so III is important for shale with low total organic carbon (TOC). III plays an important role in gas adsorption behavior [32]. Cheng and Huang's [33] evaluation of the methane adsorption capacity of Mont and Kaol at low pressure $(\leq 0.3 \mathrm{MPa})$ showed that the methane absorption of Kaol was higher than that of $\mathrm{Na}^{+}$-saturated Mont. Different orders of adsorption capacity of clay minerals have been obtained by the above scholars, mainly due to the difference in experimental instruments and sources of experimental samples. In addition, in some literature [30, 31, 34], methane adsorption was performed at low pressure even at the highest of which the methane adsorption on clay minerals did not reach saturation, and the adsorption still showed an increasing trend. The final results indicated an overestimation of methane adsorption. Therefore, high pressure based on actual reservoir pressure should be used to accurately assess the methane adsorption capacity of clay minerals [7]. Sample sources, test temperatures, and experimental conditions et al. can explain that different researchers obtain different adsorption capacity of clay minerals.

The adsorption of shale gas in the reservoir is not only on the surface of clay minerals, but also on the surface of organic matter, kerogen, cracks and matrix pores et al. Some scholars studied the adsorption of clay minerals from the perspective of whole shale reservoir and the interference other than clay minerals was not excluded 
[35]. In this study, we tried to eliminate these interferences, adopting pure clay minerals, in order to get purer effects of clay minerals on methane adsorption.

At present, many studies on the adsorption law of shale gas of clay minerals were mainly aimed at the single-gas adsorption of pure clay minerals or mixed-gas adsorption. Therefore, there is research in need for the adsorption of mixed clay minerals. However, according to the actual situation, the clay minerals contained in the shale reservoir are mixed. Therefore, based on the studies of methane adsorption of pure clay minerals, the methane adsorption of mixed clay minerals was studied, and a novel method to calculate the gas adsorption of mixed clay minerals was established, which will be more practical.

\section{Samples and methodology}

Experimental samples (Kaol, Mont, Chl, and III) were derived from American rock formations, as shown in Table 1, and were pure clay minerals, the purity and composition of which can be quantitatively analyzed by XRD $[8,36,37]$.

The XRD experiment used a powder X-ray diffractometer, $X$ Pert PRO, to test the mineral composition of the sample. The instrument uses the new super-energy detector, X Celerator, which is 100 times faster than conventional detectors. The experimental temperature was set to $25-30{ }^{\circ} \mathrm{C}$, and the collected clay mineral sample was ground into a powder before the experiment, with the required number of meshes within 320 mesh, to meet the requirements of XRD.

The low-pressure nitrogen adsorption experiment was carried out by using Conta's NOVA2000e analyzer of specific surface area and porosity. The sample was pretreated before the experiment. The sample was screened with the required sample size of 60-80 mesh and then placed in an oven at a constant temperature of $110^{\circ} \mathrm{C}$ for drying. And after about $8 \mathrm{~h}$, it was taken out to remove impurity gases in vacuum for $12 \mathrm{~h}$. After the sample preparation work was done, the experiment was carried out at a waterbathing temperature of $273 \mathrm{~K}$ and a degassing temperature of $250^{\circ} \mathrm{C}$. With liquid nitrogen having a purity more than $99.999 \%$ as an adsorption media, the isothermal adsorption-desorption experiments were performed at different relative pressures $\left(P / P_{0}\right)$ from 0.001 to 0.986 . The Brunauer, Emett Teller's BET multi-layer adsorption formula [38] could be used to perform a linear analysis at a relative pressure from 0.00 to 0.36 to obtain specific surface area which varied depending on the experimental condition and samples because the $\mathrm{N}_{2}$ adsorption was affected by the structure of clay minerals et al. [39, 40].

The methane isotherm adsorption experiment was carried out by ISOSORP-HP, the isotherm adsorption measuring instrument from Germany. There were five groups of samples, including four groups of pure clay and one group of clay mineral mixed according to the equal mass ratio of 1:1:1:1. The gas adsorption was measured with gravimetric method. The core part of the instrument is a high-precision magnetically suspended balance with an accuracy of $10 \mu \mathrm{g}$. The samples needed to be pretreated before the experiment: the samples were placed in an oven at $60^{\circ} \mathrm{C}$ for more than $24 \mathrm{~h}$ and then degassed at $100^{\circ} \mathrm{C}$ for $4 \mathrm{~h}$ in vacuum to fully remove the moisture in the sample and the impurity gas in the instrument. The experiment was performed at $61^{\circ} \mathrm{C}$, the pressure no more than $30 \mathrm{MPa}$, and the methane concentration of $99.99 \%$. During the process of pressurization, one data point was taken every 1-4 MPa until the adsorption reached the saturated state.

Finally, the Origin software was used to fit the methane adsorption data to the Langmuir-Freundlich, which was selected as a typical example of single-component adsorption models with high fitting accuracy [41, 42]. And based on this, the adsorption model of mixed minerals was obtained.

\section{Results}

\subsection{Purity analysis of clay minerals}

According to the XRD results of four clay mineral samples, as shown in Table 2, Kaol, Mont and III samples all contain a small amount of quartz and other clay minerals, but the purity is high, all greater than $91 \%$; The Chl sample contains only a very small amount of quartz, and the purity is extremely high above $97 \%$. In all, the purchased samples are of good purity.

Table 1 Source of samples

\begin{tabular}{lll}
\hline Type & Model number & Description \\
\hline Clay & Srce_Clay_KGa-1b & Kaol (low defect-Warren County Georgia USA) KGa-1b \\
Clay & Srce_Clay_SWy-3 & Na-rich Mont, Crook County, Wyoming, USA \\
Clay & Sp_Clay_CCa-2 & Ripidolite (Chl_Flagstaff Hill El Dorado County California USA) CCa-2 \\
Clay & Sp_Clay_IMt-2 & III (Silver Hill Montana USA (Cambrian Shale) Char. by Hower et al. \\
& & AmerMin. 51 pp 825-854 1966) IMt-2 \\
\hline
\end{tabular}


Table 2 XRD experimental results of clay mineral samples $\left(\times 10^{-2}\right)$

\begin{tabular}{llllrrr}
\hline Samples & Quartz & Clay & \multicolumn{4}{l}{ Relative content of clay minerals } \\
\cline { 4 - 6 } & & & III & Mont & Kaol & \multicolumn{1}{c}{ Chl } \\
\hline Kaol & 2.03 & 97.97 & 0.00 & 0.00 & 94.40 & 5.60 \\
Mont & 4.52 & 95.48 & 3.80 & 96.20 & 0.00 & 0.00 \\
Chl & 2.25 & 97.75 & 0.00 & 0.00 & 0.00 & 100.00 \\
III & 4.32 & 95.68 & 94.20 & 0.00 & 5.80 & 0.00 \\
\hline
\end{tabular}

Table 3 Pore structure parameters

\begin{tabular}{lcl}
\hline Samples & Specific surface area $/\left(\mathrm{m}^{2} \mathrm{~g}^{-1}\right)$ & $\begin{array}{l}\text { Pore } \\
\text { volume/ } \\
\left(\mathrm{cc} \mathrm{g}^{-1}\right)\end{array}$ \\
\hline Kaol & 11.927 & 0.07338 \\
Mont & 6.029 & 0.02658 \\
Chl & 5.318 & 0.02488 \\
III & 11.382 & 0.03300 \\
\hline
\end{tabular}

\subsection{Parameters of pore structure}

According to Table 3, the order of the specific surface area of clay minerals is: $\mathrm{Kaol}>\mathrm{III}>\mathrm{Mont}>\mathrm{Chl}$, and the pore volume also conforms to this order. Thus, there is a certain positive correlation between them. The conclusion is different from some results in the literature, such as Liang et al. [9] and Li-Ming et al. [43], which is mainly caused by the difference in properties of clay minerals and experiment condition et al. For example, different properties can result in different microstructure because even the same type of minerals can come from different reservoirs with many samples, such as Mont, which can be divided

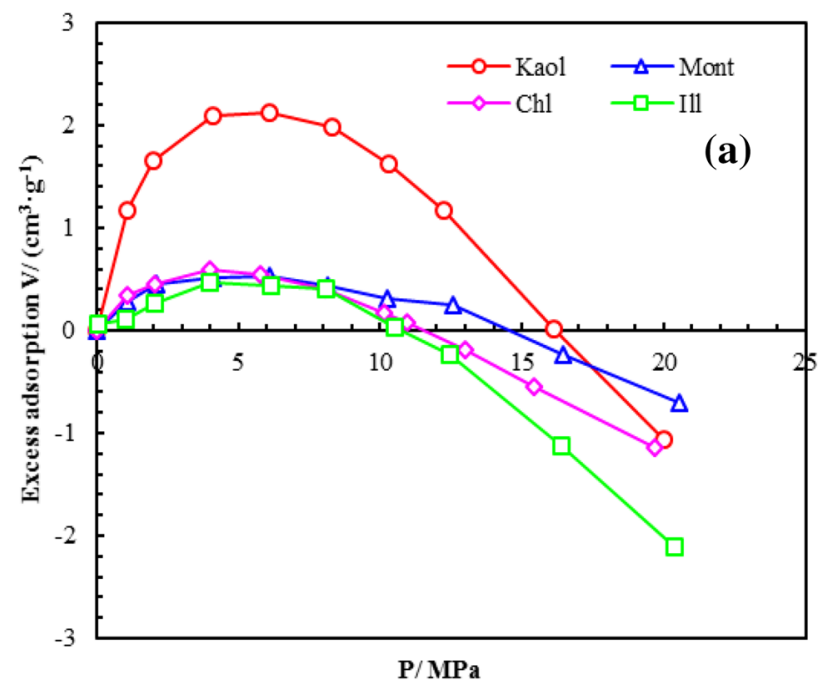

into $\mathrm{Ca}^{2+}$-Mont and $\mathrm{Na}^{+}$-Mont etc. $[33,39,40]$. The samples used by authors and scholars in the literature are all from different reservoirs, and we have obtained different results. Thus, the order and relation are almost related to the mineral sample itself. The conclusion here is mainly for the samples in this experiment, and it is of certain reference significance to other related research.

\subsection{Methane isothermal adsorption}

Only the excess adsorption isotherm can be obtained by any conventional gas adsorption measurement (gravimetric method, manometry, etc.) [16]. The observed Gibbs excess adsorption is different from the absolute adsorption (actual adsorption) [44-48]. However, the adsorption models used in this paper all describe the absolute adsorption, which is not available for the excess adsorption [49]. The excess adsorption isotherm of clay minerals is shown in Fig. 1 a.

The key parameters for conversion between the excess and absolute adsorption are $V_{a}$ (adsorption phase volume) or $\rho_{a}$ (adsorption phase density). However, any method cannot directly measure $V_{a}$ and $\rho_{a}$. The conversion formula is as follows $[16,49,50]$ :

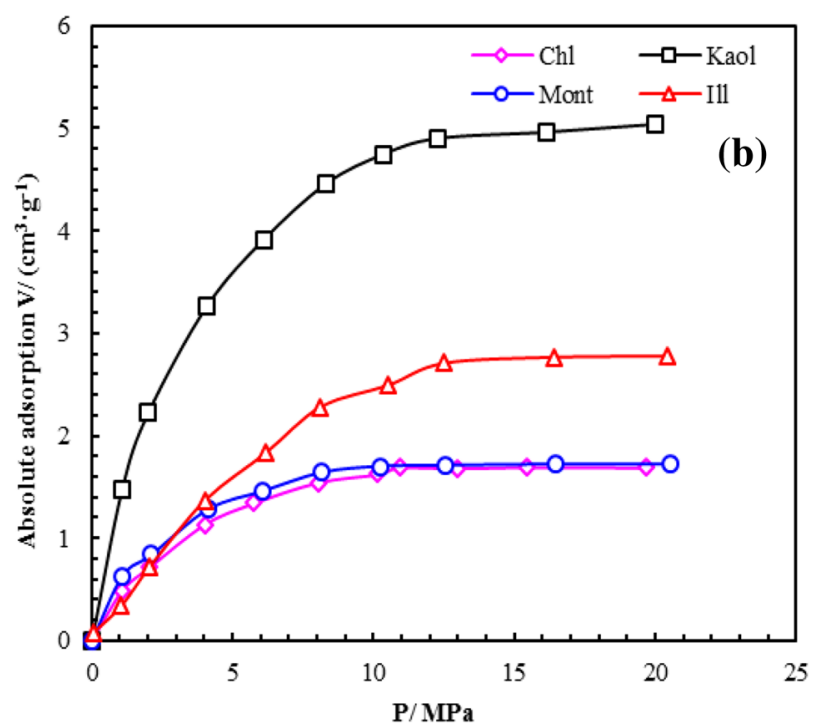

Fig. 1 Adsorption isotherm of pure clay minerals 
$m_{a b s}=m_{\text {excess }}+V_{a} \times \rho_{g}$

or:

$m_{a b s}=\frac{m_{\text {excess }}}{1-\frac{\rho_{g}}{\rho_{a}}}$.

The absolute adsorption isotherm was obtained through the software of equipment, as shown in Fig. $1 \mathrm{~b}$. According to the six types of adsorption isothermal summarized by IUPAC [51], the absolute adsorption isotherm of four clay minerals belongs to type I [6]. The absolute methane adsorption monotonically increases faster under low pressure than high pressure. Finally, when the pressure is large enough, the absolute adsorption will no longer increase as the pressure rises. The maximum absolute adsorption of four clay minerals were: Kaol $5.04 \mathrm{~cm}^{3} \mathrm{~g}^{-1}>$ III $2.78 \mathrm{~cm}^{3} \mathrm{~g}^{-1}>$ Mont $1.72 \mathrm{~cm}^{3} \mathrm{~g}^{-1}>\mathrm{Chl}$ $1.69 \mathrm{~cm}^{3} \mathrm{~g}^{-1}$. The result is different from other scholars' results, such as Ji et al. [26, 27], Liu et al. [7], Ross and Bustin [30], which are also mainly related to the difference in the properties of the samples and experiment condition et al.

According to Fig. 2, the specific surface area of the clay mineral is positively correlated to the maximum absolute adsorption. Therefore, the larger the specific surface area of the clay mineral, the larger the methane adsorption. The surface of mineral pores can provide adsorption sites for methane. The specific surface area of clay minerals determines the number of adsorption sites. The more adsorption sites there are, the stronger the adsorption capacity is. This shows that the specific surface area of

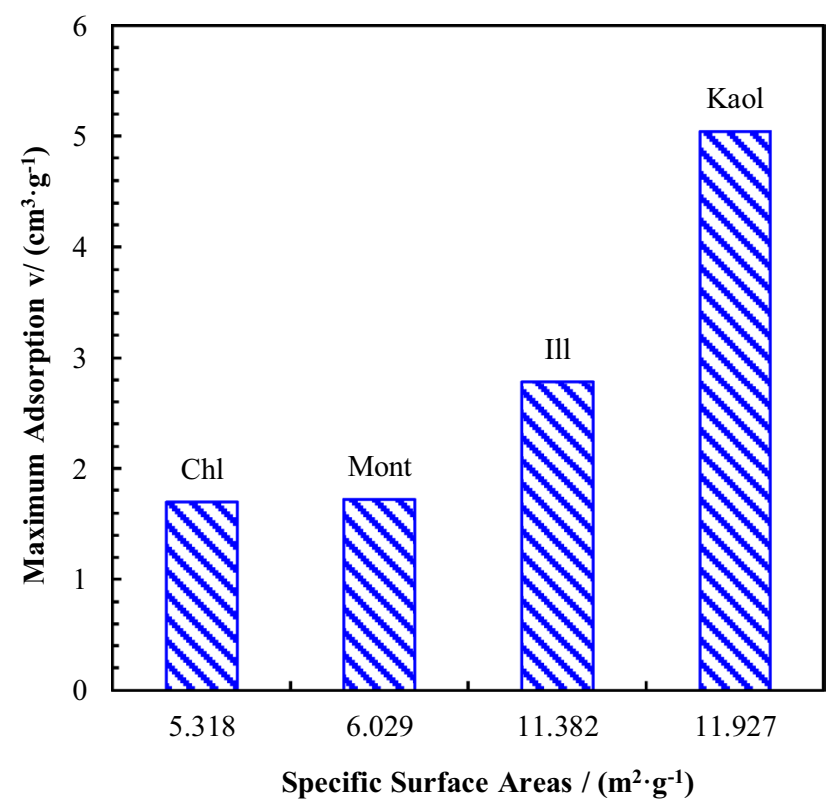

Fig. 2 Specific surface area-maximum adsorption clay minerals determines the adsorption capacity to some extent $[16-21,26,27]$. At present, some studies suggested that the mesopores of clay minerals provide the main storage space for gas [52], while some studies believed that minerals affect the adsorption capacity of shale through the volume of micropores and mesopores, and that pores with a diameter below $20 \mathrm{~nm}$ are the main gas adsorption place $[22,24]$. However, the specific effect of pore size on methane adsorption should be further discussed in future studies, to further understand the effect of pore structure parameters on methane adsorption of clay minerals.

\section{Adsorption calculation model of mixed minerals}

\subsection{Establishment of model}

Only the methane adsorption measurement was performed in this paper. Thus, the single-component adsorption model, Langmuir-Freundlich [53], was used to fit the adsorption data as follows:

Langmuir-Freundlich:

$V=\frac{V_{L}(b P)^{m}}{1+(b P)^{m}}$.

The data was respectively fitted to Langmuir-Freundlich by Origin in Fig. 3, with the fitting parameters of the model shown in Table 4. It can be seen that the fitting correlation coefficients $R^{2}$ of four clay minerals are greater than 0.99 with pretty good effect.

For the establishment of adsorption calculation model of the mixed minerals, the theoretical parameters of the mixed minerals adsorption model were obtained by summing the adsorption model parameters of the pure clay

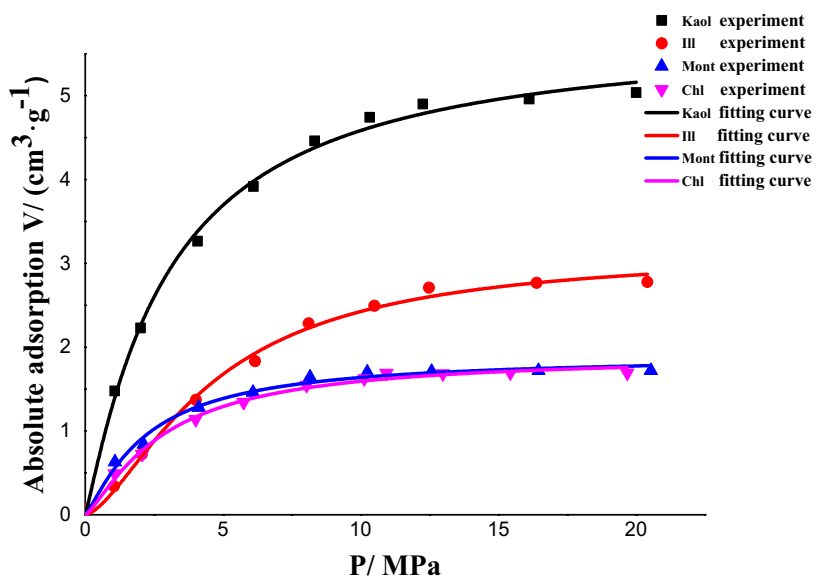

Fig. 3 Fitting of Langmuir-Freundlich 
Table 4 Fitting parameters of Langmuir-Freundlich

\begin{tabular}{llllll}
\hline Model & Parameters & Kaol & Mont & Chl & III \\
\hline $\begin{array}{c}\text { Langmuir- } \\
\text { Freundlich }\end{array}$ & $V_{L} /\left(\mathrm{cm}^{3} \mathrm{~g}^{-1}\right)$ & 5.7839 & 1.8948 & 1.9014 & 3.1535 \\
& $b$ & 0.3332 & 0.4547 & 0.3574 & 0.2168 \\
& $m$ & 1.1133 & 1.2204 & 1.2865 & 1.5526 \\
& $\mathrm{R}^{2}$ & 0.9963 & 0.9978 & 0.9931 & 0.9945 \\
\hline
\end{tabular}

minerals contained in the mixture according to their constituent mass ratio, as shown in the following formula:

$K=\sum_{i=1}^{n} K_{i} y_{i}$

The Langmuir-Freundlich was used in this research. According to (4), the parameters of the mixed minerals were obtained by summing the parameters of Langmuir-Freundlich of the pure clay minerals respectively according to the mass ratio (1:1:1:1):

$V_{L}=V_{L 1} \times y_{1}+V_{L 2} \times y_{2}+V_{L 3} \times y_{3}+V_{L 4} \times y_{4}$

$b=b_{1} \times y_{1}+b_{2} \times y_{2}+b_{3} \times y_{3}+b_{4} \times y_{4}$

$m=m_{1} \times y_{1}+m_{2} \times y_{2}+m_{3} \times y_{3}+m_{4} \times y_{4}$.

According to (5)-(7), it can be obtained combined with the data in Table 4:

$V_{L}=3.1834$

$b=0.3405$

$m=1.2932$.

In summary, the Langmuir-Freundlich adsorption model of mixed clay minerals can be obtained as follows:

$V=\frac{3.1834 \times(0.3405 \times P)^{1.2932}}{1+(0.3405 \times P)^{1.2932}}$.

The theoretical values are compared with the actual data as shown in Fig. 4. The error is $4.23 \%$ with the high degree of fitting. Therefore, this method is feasible in this experiment.

\subsection{Verification of model}

The methane adsorption data of $\mathrm{Chl}, \mathrm{III}$, and $\mathrm{Chl}-\mathrm{III}$ at $60^{\circ} \mathrm{C}$ by Xiong Jian [54] was used to verify the calculation model also by using Langmuir-Freundlich [53]. The fitting image in Fig. 5 and fitting parameters in Table 5 are as follows with $R^{2}$ values of two clay minerals greater than 0.99 .

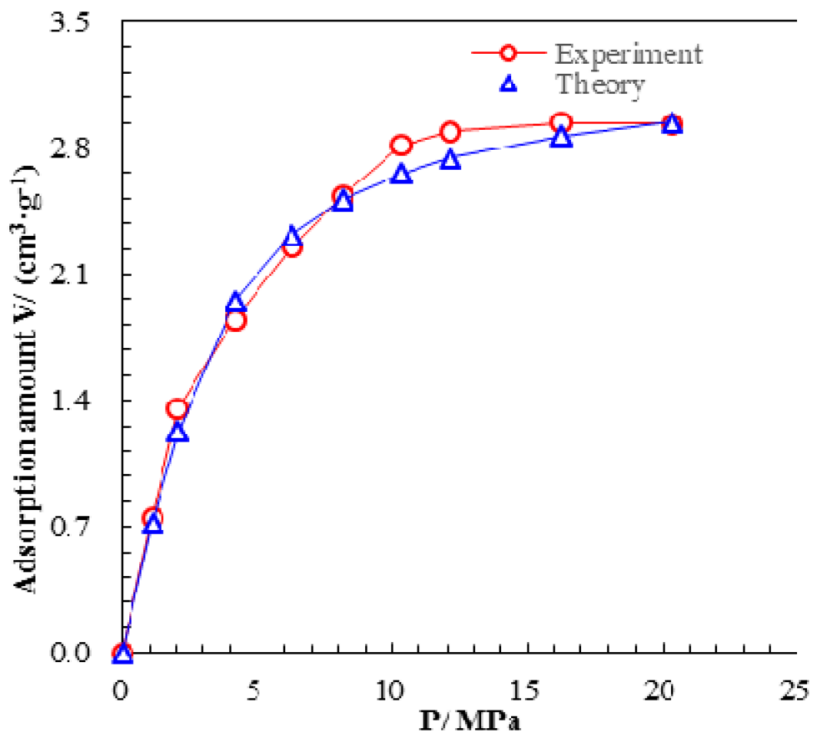

Fig. 4 comparison between theoretical values and actual data

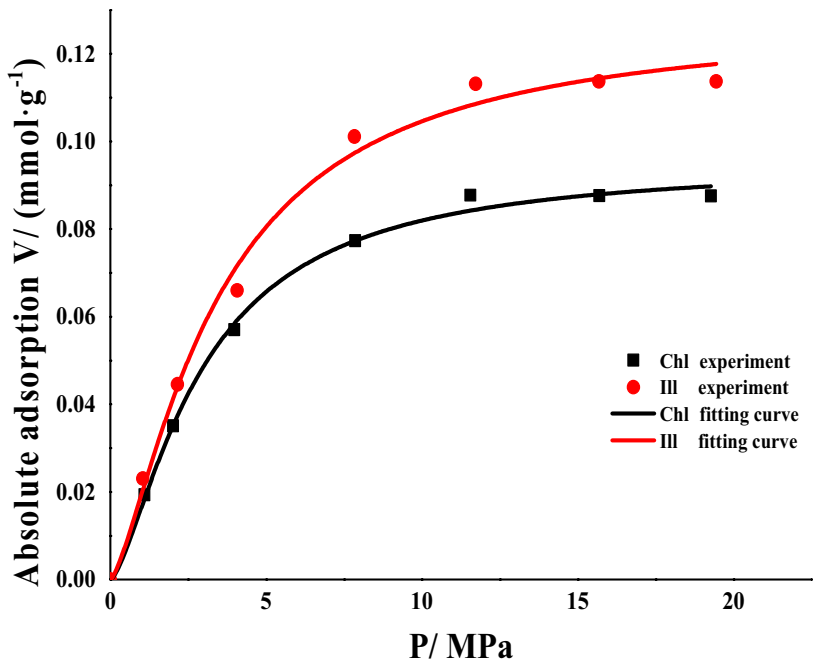

Fig. 5 Fitting of Langmuir-Freundlich

Table 5 Fitting parameters of Langmuir-Freundlich

\begin{tabular}{llll}
\hline Model & Parameters & Chl & III \\
\hline $\begin{array}{llll}\text { Langmuir-Freun- } \\
\text { dlich }\end{array}$ & $V_{L} /\left(\mathrm{cm}^{3} \mathrm{~g}^{-1}\right)$ & 0.0954 & 0.1281 \\
& $b$ & 0.3431 & 0.2910 \\
& $m$ & 1.4658 & 1.3957 \\
& $\mathrm{R}^{2}$ & 0.9966 & 0.9913 \\
\hline
\end{tabular}

The Langmuir-Freundlich was used for verification. In the literature, the clay minerals were also mixed in equal mass ratio (1:1), and it can be obtained referring to (4): 
$V_{L}=V_{L 1} \times y_{1}+V_{L 2} \times y_{2}$

$b=b_{1} \times y_{1}+b_{2} \times y_{2}$

$m=m_{1} \times y_{1}+m_{2} \times y_{2}$.

According to (9)-(11), it can be obtained combined with the data in Table 5:

$V_{L}=0.1118$

$b=0.3171$

$m=1.4308$.

In summary, the Langmuir-Freundlich of mixed clay minerals can be obtained as follows:

$V=\frac{0.1118 \times(0.3171 \times P)^{1.4308}}{1+(0.3171 \times P)^{1.4308}}$.

The theoretical values were compared with the actual data as shown in Fig. 6 . The error is $7 \%$ with the high degree of fitting. Therefore, it has been verified that the adsorption model parameters of the mixed clay minerals can be obtained by summing the parameters of the pure minerals contained in the mixture according to the constituent mass ratio.

\subsection{Analysis of sensitivity}

By comparing the theoretical adsorption of the mixed minerals calculated through the above method at the highest experimental pressure, the effect of each pure mineral on the adsorption of mixed minerals was studied

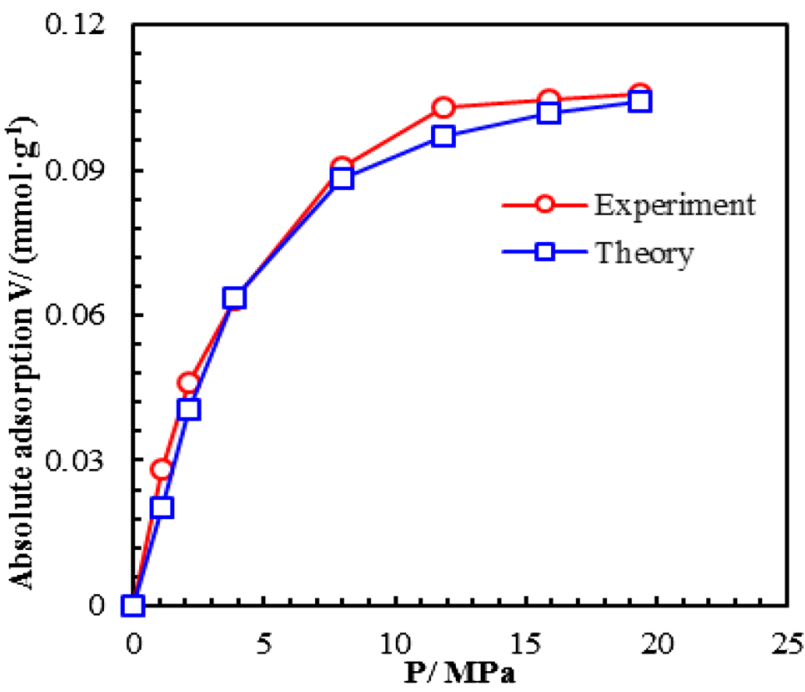

Fig. 6 Comparison between theoretical values and actual data through separately increasing the mass ratio of each pure clay mineral in the mixed minerals respectively. (The content of each pure mineral was gradually increased from the original $1-5$ shares in the mixed minerals, and during the increase, the other three minerals still respectively account for one share in the mixed minerals.) From Fig. 7, the change of the mass ratio of III has almost no effect on the adsorption of mixed minerals which varies obviously with the increase of the mass ratio of Kaol, Mont and Chl. According to the theoretical calculation, it can be seen that in this study, the adsorption of mixed minerals is less sensitive to the content of III than Kaol, Mont and Chl.

\section{Discussions}

Many adsorption studies were conducted for multi-component gas mixtures. The gas adsorption in porous media is not only affected by the pore structure but also the interaction between molecules. Due to the different type of gas, the interaction force between molecules is different as well as between molecules and pore walls, and competitive adsorption occurs. The configuration and density distribution of adsorbate molecules in the pores are also impacted, appearing in different states.

Hall et al. [55] used the volumetric method to test the adsorption isotherms of pure components including methane, nitrogen, carbon dioxide and their binary mixtures in water-bearing coal. When the adsorption of any component in the mixed gas was calculated, it was determined based on the mass ratio and adsorption of the corresponding pure component. However, the final results showed that the measured adsorption of the

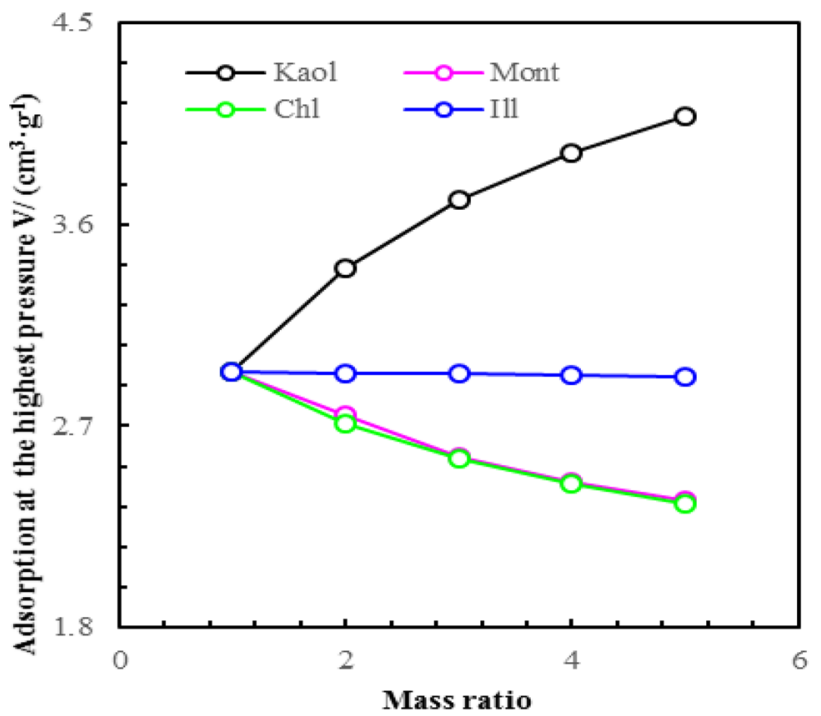

Fig. 7 Analysis of sensitivity 
mixed gas cannot be calculated by simply summing the adsorption of pure components according to their ratio, otherwise it will cause a big error. The influence of intermolecular force, and the interaction between molecules and pore walls are vectors and cannot be predicted by simple addition. Thus, there will exist big error between the theoretical adsorption calculated by this method and actual value of the multi-component gas. In this paper, the single-component gas, methane, was used to study the adsorption law of mixed mineral. Finally, the methane adsorption of mixed minerals can be calculated by summing the adsorption of pure minerals according to the mass ration with small error, which was also verified by the data in the literature. The difference in methane adsorption capacity of different minerals is caused by differences in pore structure characteristics. The adsorption of minerals is mainly controlled by its pore structure which affects adsorption through factors such as pore volume, shape and specific surface area. These can be seen as scalars, so the results obtained in this paper are credible.

\section{Conclusions}

In order to establish a novel method to calculate the gas adsorption of mixed clay minerals and study the adsorption difference among pure clay minerals, a series of experiments were performed. XRD and low-pressure nitrogen adsorption showed the physical properties of clay minerals: the purity of samples is all more than $90 \%$; the order of specific surface area is: Kaol $>$ III $>$ Mont $>$ Chl, as well as pore volume. The methane isothermal adsorption showed the order of adsorption: Kaol $>$ III $>$ Mont $>$ Chl, which is positively correlated to specific surface area. The adsorption model of mixed minerals was established by Langmuir-Freundlich. The result showed that the model parameters of the mixed clay minerals can be obtained by summing the parameters of the pure minerals contained in the mixture according to their constituent mass ratio, which was also verified by literature data. It was found that the effect of III on the adsorption of mixed minerals is smaller than that of Kaol, Mont and Chl. In Summary, as long as the mass ratio in mixed clay minerals gets known, the theoretical adsorption of mixed minerals can be calculated.

Acknowledgements The National Natural Science Foundation greatly provides the financial support for this research. Fan Zhang is acknowledged for her assistance in collecting experimental data.

Author contributions ZW and YZ: These authors contributed equally to this work.
Funding This work was supported by the National Natural Science Foundation (Grant No. 51836003).

\section{Compliance with ethical standards}

Conflict of interest The authors declare no competing financial interest.

\section{References}

1. Curtis JB (2002) Fractured shale-gas systems. AAPG Bull 86(11):1921-1938

2. Jing W, Huiqing L, Rongna G, Aihong K, Mi Z (2011) A new technology for the exploration of shale gas reservoirs. Pet Sci Technol 29(23):2450-2459

3. Montgomery SL, Jarvie DM, Bowker KA, Pollastro RM (2005) Mississippian Barnett Shale, Fort Worth basin, north-central Texas: gas-shale play with multi-trillion cubic foot potential. AAPG Bull 89(2):155-175

4. Bowker KA (2003) Recent development of the Barnett shale play, Fort Worth Basin: West Texas. Geol Soc Bull 42:1-11

5. Jarvie DM, Hill RJ, Ruble TE, Pollastro RM (2007) Unconventional shale-gas systems: the Mississippian Barnett shale of north-central Texas as one model for thermogenic shale-gas assessment. AAPG Bull 91:475-499

6. Wang Q, Huang L (2019) Molecular insight into competitive adsorption of methane and carbon dioxide in montmorillonite: effect of clay structure and water content. Fuel 239:32-43

7. Liu D, Yuan P, Liu H, Li T, Tan D, Yuan W et al (2013) High-pressure adsorption of methane on montmorillonite, kaolinite and illite. Appl Clay Sci 85(Complete):25-30

8. Chen S, Han Y, Fu C, Zhang H, Zhu Y, Zuo Z (2016) Micro and nano-size pores of clay minerals in shale reservoirs: implication for the accumulation of shale gas. Sediment Geol 342:180-190

9. Liang L, Xiong J, Liu X, Luo D (2016) An investigation into the thermodynamic characteristics of methane adsorption on different clay minerals. J Nat Gas Sci Eng 33:1046-1055

10. Bustin RM, Clarkson CR (1998) Geological controls on coalbed methane reservoir capacity and gas content. Int J Coal Geol 38:3-26

11. Wang SB, Song ZG, Cao TT, Song X (2013) The methane sorption capacity of Paleozoic shales from the SichuanBasin, China. Mar Pet Geol 44:112-119

12. Ji LM, Zhang TW, Milliken KL, Qu JL, Zhong XL (2012) Experimental investigation of main controls to methane adsorption in clay-rich rocks. Appl Geochem 27:2533-2545

13. Schettler PD, Parmoly CR (1990) The measurement of gas desorption isotherms for Devonian shale. GRI Devonian Gas Shale Technol Rev 7:4-9

14. Hao F, Zou H, Lu Y (2013) Mechanisms of shale gas storage: implications for shale gas exploration in China. AAPG Bull 97:1325-1346

15. Yang W, Chen G, Lu C, Zhong J, Xu Y, Yang S, Xue L (2015) Micropore characteristics of the organic rich shale in the 7th member of the Yanchang Formation in the southeast of Ordos Basin. Nat Gas Geosci 26(418-426):591

16. Gasparik M, Bertier P, Gensterblum Y, Ghanizadeh A, Krooss BM, Littke R (2014) Geological controls on the methane storage capacity in organic-rich shales. Int J Coal Geol 123(2):34-51

17. Loucks RG, Ruppel SC (2007) Mississippian barnett shale: lithofacies and depositional setting of a deep-water shale-gas succession in the fort worth basin, Texas. AAPG Bull 91(4):579-601 
18. Ross DJK, Bustin RM (2008) Characterizing the shale gas resource potential of Devonian-Mississippian strata in the western Canada Sedimentary Basin: application of an integrated formation evaluation. AAPG Bull 92(1):87-125

19. LiT, Wu CF (2015) Research on the abnormal isothermal adsorption of shale. Energy Fuel 29(2):634-640

20. Chattaraj S, Mohanty D, Kumar T, Halder G (2016) Thermodynamics, kinetics and modeling of sorption behavior of coalbed methane-A review. J Unconv Oil Gas Resour 16:14-33

21. Gasparik M, Ghanizadeh A, Bertier P, Gensterblum Y, Bouw S, Krooss BM (2012) High-pressure methane sorption isotherms of black shales from the Netherlands. Energy Fuels 26:4995-5004

22. Yang F, Ning Z, Zhang R, Zhao H, Krooss BM (2015) Investigations on the methane sorption capacity of marine shales from Sichuan Basin, China. Int J Coal Geol 146:104-117

23. Rexer TF, Mathia EJ, Aplin AC, Thomas KM (2014) High pressure methane adsorption and characterization of pores in Posidonia shales and isolated kerogens. Energy Fuels 28(5):2886-2901

24. Ji L, Qiu J, Xia Y, Zhang T (2012) Micro-pore characteristics and methane adsorption properties of common clay minerals by electron microscope scanning. Acta Pet Sin 33:249-256

25. Tang S, Fan E (2014) Methane adsorption characteristics of clay minerals in organic-rich shales. J China Coal Soc 39:1700-1706

26. Ji L, Qiu J, Zhang T, Xia Y (2012) Relationship between methane adsorption capacity of clay minerals and micropore volume. Nat Gas Geosci 37(5):1043-1050

27. Ji L, Ma X, Xia Y, Qiu J (2013) Experiments on methane adsorption of common clay minerals in shale. Nat Gas Geosci 25(2):141-152

28. Chalmers GRL, Bustin RM (2008) Lower Cretaceous gas shales in northeastern British Columbia, part II: evaluation of regional potential gas resources. Bull Can Pet Geol 56(1):22-61

29. Zhang T, Ellis GS, Ruppel SC, Milliken K, Yang R (2012) Effect of organic-matter type and thermal maturity on methane adsorption in shale-gas systems. Org Geochem 47:120-131

30. Ross DJK, Bustin RM (2009) The importance of shale composition and pore structure upon gas storage potential of shale gas reservoirs. Mar Pet Geol 26(6):916-927

31. Lu XC, Li FC, Watson AT (1995) Adsorption measurements in Devonian shales. Fuel 74(4):599-603

32. Zhang J, Guohui C, Clennell MB, Dewhurst DN, Keyu L, Marina P (2016) Methane and carbon dioxide adsorption on illite. Energy Fuels 30(12):10643-10652

33. Cheng AL, Huang WL (2004) Selective adsorption of hydrocarbon gases on clays and organic matter. Org Geochem 35(4):413-423

34. Ross DJK, Bustin RM (2007) Shale gas potential of the Lower Jurassic Gordondale Member, northeastern British Columbia, Canada. Bull Can Pet Geol 55(1):51-75

35. Ji W, Song Y, Jiang Z, Wang X, Bai Y, Xing J (2014) Geological controls and estimation algorithms of lacustrine shale gas adsorption capacity: a case study of the Triassic strata in the southeastern Ordos Basin, China. Int J Coal Geol 134-135:61-73

36. Shi J, Shen G, Zhao H, Sun N, Song X, Guo Y et al (2018) Porosity at the interface of organic matter and mineral components contribute significantly to gas adsorption on shales. $\mathrm{J} \mathrm{CO}_{2}$ Util 28:73-82

37. Li A, Ding W, Zhou X, Cao X, Zhang M, Fu F et al (2017) Investigation of the methane adsorption characteristics of marine shale: a case study of Lower Cambrian Qiongzhusi Shale in eastern Yunnan Province, South China. Energy Fuels 31(3):2625-2635

38. Brunauer S, Emmett PH, Teller E (1938) Adsorption of gases in multi-molecular layers. J Am Chem Soc 60(2):309-319
39. Aylmore L, Sills I, Quirk J (1970) Surface area of homoionic illite and montmorillonite clay minerals as measured by the sorption of nitrogen and carbon dioxide. Clay Clay Miner 18:91-96

40. Michot LJ, Villieras F (2006) Surface area and porosity. In: Bergaya $F$, Theng BKG, Lagaly $G$ (eds) Handbook of clay science. Developments in Clay Science, vol 1. Elsevier, Amsterdam, pp 965-972

41. Zhao TY, Ning ZF, Zeng Y (2014) Comparative analysis of isothermal adsorption models for shale and coals[J]. Xinjiang Pet Geol 35(3):319-323

42. Li Y (2017) Microscopic mechanism of adsorption and diffusion of C7 shale gas reservoirs [D]. Southwest Petroleum University, Chengdu

43. Li-Ming Jl, Jun-Li QU, Zhi-Guang S, Yan-Qing X (2014) Impact of internal surface area of pores in clay rocks on their adsorption capacity of methane. Geochimica 43:238-244

44. Zhou L, Zhou Y, Li M, Chen P, Wang Y (2000) Experimental and modeling study of the adsorption of supercritical methane on a high surface activated carbon. Langmuir 16(14):5955-5959

45. Zhou L, Bai S, Su W, Yang J, Zhou Y (2003) Comparative study of the excess versus absolute adsorption of $\mathrm{CO}_{2}$ on superactivated carbon for the near-critical region. Langmuir 19(7):2683-2690

46. Gensterblum $Y$, van Hemert $P$, Billemont $P$, Battistutta $E$, Busch $A$, Krooss BM et al (2010) European inter-laboratory comparison of high pressure $\mathrm{CO}_{2}$ sorption isotherms II: natural coals. Int J Coal Geol 84(2):115-124

47. Clarkson CR, Haghshenas B (2013) Modeling of supercritical fluid adsorption on organic-rich shales and coal. In: SPE unconventional resources conference, Woodlands, Texas

48. Heller R, Zoback M (2014) Adsorption of methane and carbon dioxide on gas shale and pure mineral samples. J Unconv Oil Gas Resour 8:14-24

49. Zhou S, Xue H, Ning Y, Guo W, Zhang Q (2018) Experimental study of supercritical methane adsorption in Longmaxi shale: insights into the density of adsorbed methane. Fuel 211:140-148

50. Liu Y, Li HA, Tian Y, Jin Z, Deng H (2018) Determination of the absolute adsorption/desorption isotherms of $\mathrm{CH}_{4}$, and n- $\mathrm{C}_{4} \mathrm{H}_{10}$, on shale from a nano-scale perspective. Fuel 218:67-77

51. Brunauer S, Deming L, Deming W, Teller E (1940) Adsorption isotherm IUPAC. Am Chem Soc 62:1723

52. Li QZ, Cai YL, Hu HY (2017) Characteristics of nanopore structure of clay minerals in shale and its effects on methane adsorption capacity[J]. J China Coal Soc 42(9):2414-2419

53. Quiñones I, Guiochon G (1998) Extension of a Jovanovic-Freundlich isotherm model to multicomponent adsorption on heterogeneous surfaces. J Chromatogr A 796(1):15-40

54. Xiong J (2015) Investigation of the influences of the methane adsorption capacity on shale. Southwest Petroleum University, Chengdu

55. Hall FE, Zhou C, Gasem KAM et al (1994) Adsorption of pure methane, nitrogen, carbon dioxide and their mixtures on wet Fruitland coal. In: Spe Eastern Regional Conference proceedings of the 1994 Spe Eastern Regional Conference, pp 2351-2363

Publisher's Note Springer Nature remains neutral with regard to jurisdictional claims in published maps and institutional affiliations. 